\title{
HARMONIE-AROME single-column tools and experiments
}

\author{
Emily Gleeson $^{1}$, Stephen Outten ${ }^{2}$, Bjørg Jenny Kokkvoll Engdahl ${ }^{3}$, Eoin Whelan ${ }^{1}$, Ulf Andrae ${ }^{4}$, and \\ Laura Rontu ${ }^{5}$ \\ ${ }^{1}$ Met Éireann, Glasnevin Hill, Dublin 9, D09 Y921, Ireland \\ ${ }^{2}$ Nansen Environmental and Remote Sensing Centre, Thormøhlens gate 47, 5006, Bergen, Norway \\ ${ }^{3}$ Norwegian Meteorological Institute, P.O. Box 43, Blindern 0313, Oslo, Norway \\ ${ }^{4}$ Swedish Meteorological Hydrological Institute, 60176 Norrköping, Sweden \\ ${ }^{5}$ Finnish Meteorological Institute, Helsinki, Finland \\ Correspondence: Emily Gleeson (emily.gleeson@met.ie)
}

Received: 13 March 2020 - Revised: 5 October 2020 - Accepted: 29 October 2020 - Published: 16 November 2020

\begin{abstract}
The single-column version of the shared ALADIN-HIRLAM numerical weather prediction system, called MUSC, was developed by Météo-France in the 2000s and has a growing user-base in both HIRLAM and ALADIN countries. Tools to derive the required input, to run the experiments and to handle outputs of experiments carried out using MUSC have been developed within the HARMONIE-AROME canonical model configuration of the ALADIN-HIRLAM system are described within and constitute a large portion of this paper. The paper also illustrates the usefulness of the single-column approach for testing and developing HARMONIEAROME physical parametrizations related to cloud microphysics and radiative transfer. Study cases concerning these physical parametrizations have been included for illustration purposes.
\end{abstract}

\section{Introduction}

In a Numerical Weather Prediction (NWP) system the dynamical and physical processes are split into vertical and horizontal contributions. For physical processes, the horizontal contributions are neglected. This makes it possible to separate a column from the full, three-dimensional system to form a single-column model which retains all of the science, algorithms and software of the full model. A single-column environment has many advantages. Because the calculations are done in a single vertical column, computations are very fast. This makes such models extremely useful for testing and developing new code and physical parametrizations and for carrying out sensitivity tests. It is easy to replace physical parametrizations by prescribed forcings within the singlecolumn so that the influence of possible (compensating) errors from those parametrizations can be avoided. Some of the disadvantages of single-column models are that it is easy to drift away from a realistic atmospheric state, the results rely heavily on the large-scale forcings, there is no interaction with the large-scale flow and it is unsuitable for use in weather forecasting. Nevertheless, the advantages are clear for those testing and developing physical parametrizations.

Most major global NWP models have a corresponding single-column set-up. For example the ECMWF Integrated Forecasting System (IFS) single-column model is documented at https://confluence.ecmwf.int/display/OIFS/ Single+column+model+43r3+release+notes (last access: 14 November 2020). Likewise the UK Met Office's Unified Model (UM, Walters et al., 2011) can be run in singlecolumn mode as can the Global Forecast System (GFS; Global Model Test Bed single column model, Firl et al., 2019).

The shared ALADIN-HIRLAM Numerical Weather Prediction System (hereafter the ALADIN-HIRLAM NWP system, Termonia et al., 2018) is developed, maintained and validated by a collaboration of 26 countries in Europe and Northern Africa with the main focus on short-range mesoscale NWP. The single-column version of the ALADINHIRLAM NWP system is known as MUSC - Modèle Unifié Simple Colonne. MUSC was originally developed by Météo- 
France in the 2000s - see Malardel (2004) for a description of the pseudo-1D application of the 2D meridional vertical plane Limited Area Model (LAM) configuration. Further maintenance and development of MUSC has been carried out over the years for specific one-dimensional model inter-comparisons and physics validations. MUSC was developed because Météo-France's collaboration with the ALADIN and HIRLAM consortia resulted in an NWP system, now called the ALADIN-HIRLAM NWP system, which contains a range of options for physical parametrizations. The idea to have a common one-dimensional tool was put forward so that the various consortia could test their physics parametrizations and carry out their own inter-comparison studies. Nevertheless, MUSC remains vastly under-utilised within the ALADIN-HIRLAM modelling community. However, work by the authors of this paper, on making the 1D system more user-friendly, has led to improvements in its usability. The Malardel (2004) documentation is the official reference for MUSC and plans to write more extensive documentation are currently under consideration.

Single-column models are used widely for teaching and education. For example, in 2013 MUSC was used for a laboratory course on numerical meteorology, arranged jointly by the University of Helsinki and the Finnish Meteorological Institute (FMI). In 2016 the Finnish non-profit state-owned company, CSC, installed a version of MUSC on their cPouta cloud service platform in collaboration with the Norwegian Meteorological Institute (Met Norway) and the Swedish Meteorological Hydrological Institute (SMHI). The main benefit of this was to remove the need for users to carry out the time-consuming and laborious task of installing MUSC on their local machines (Koski, 2017). Recently, Stephen Outten and colleagues at the Nansen Environmental and Remote Sensing Centre (NERSC) in Norway created a MUSC virtual machine (VM). Further details on this can be found in Sect. 3.4.

There are three canonical model configurations (CMCs) of the ALADIN-HIRLAM NWP system. The CMC used by the authors of this paper is known as HARMONIE-AROME (Bengtsson et al., 2017). The software discussed in this paper was developed using the HARMONIE-AROME CMC and is available as a utility of the NWP system. Other than that, MUSC uses the same source code and scripting system as 3D HARMONIE-AROME which means that it continuously benefits from model upgrades and developments i.e. MUSC is automatically updated with every 3D cycle of the model.

As well as the documentation by Malardel (2004), results of studies done using MUSC are widely documented. For example, Météo-France has been involved in many international single-column model inter-comparisons such as the various iterations of GABLS (Global Energy and Water cycle EXperiment Atmospheric Boundary Layer Study, Cuxart et al., 2006; Svensson et al., 2011; Bosveld et al., 2014; Vignon et al., 2017) and GASS/EUCLIPSE (Neggers et al., 2017). In such cases MUSC is run in prognostic mode using realistic atmospheric and/or surface forcings allowing comparisons with observations.

Remnant documentation and presentation slides from a MUSC training course held at FMI in 2011 are available at http://netfam.fmi.fi/muscwd11/ (last access: 14 November 2020) and http://netfam.fmi.fi/muscwd11/Agenda.html (last access: 14 November 2020). Further presentations and exercise material involving MUSC is available in the 2nd AROME training course repository: http://www.umr-cnrm. fr/gmapdoc/spip.php?rubrique64 (last access: 14 November 2020). At the Dutch Meteorological Institute (KNMI) MUSC is run as a testbed and documented in Neggers and Siebesma (2010). Under the HARMONIE-AROME CMC, MUSC has been used for several physical parametrizations studies e.g. glaciers (Mottram et al., 2017), radiative transfer (Nielsen et al., 2014) and aerosols (Gleeson et al., 2016; Rontu et al., 2020). The results of some of the test cases may be of interest to scientists working on parametrizations in other models as has previously been the case in intercomparison studies such as GABLS.

The aim of this paper is to describe some of the tools and scripts we have used and developed in order to make MUSC more use-friendly. We also illustrate the use of the singlecolumn approach for testing and developing HARMONIEAROME physical parametrizations related to cloud microphysics and radiative transfer. The study cases included are mostly documented in other published papers and are included here for illustration purposes rather than an in-depth analysis compared to observations. Note that this paper is not the official documentation of MUSC, nor is it intended to be a practical guide for single-column studies. The paper is organised as follows: Sect. 2 provides a summary of the shared ALADIN HIRLAM NWP system. Section 3 contains information about using MUSC in the HARMONIEAROME environment and includes details about preparing input and namelists for MUSC (Sect. 3.1), handling outputs from MUSC (Sect. 3.2), the HARMONIE-AROME MUSC script system (Sect. 3.3) and the MUSC virtual machine (Sect. 3.4). Section 4 describes some single-column study cases. The conclusions and outlook are presented in Sect. 5.

\section{Description of cycle 43 of the ALADIN-HIRLAM NWP system}

The development of the MUSC related tools, namelists and input files has been carried using cycle 43 of the ALADINHIRLAM NWP System. Section 2 of Termonia et al. (2018) provides a description of the code architecture, the concept of cycles and the code's relationship to the global models of ECMWF (IFS) and Météo-France (ARPEGE). Common code used by IFS and ARPEGE is updated with Limited Area Model (LAM) specific code, used by Météo-France and the ALADIN and HIRLAM NWP consortia, approximately once per year to create an export version. The so-called export ver- 
sions are taken as the basis for a new ALADIN-HIRLAM NWP System release. The ALADIN-HIRLAM NWP System also provides extra HARMONIE-AROME specific code developments, a build system, a scripting system, a namelist generator and extra utilities to provide a system that can execute anything from MUSC experiments to the full operational implementation of an ensemble prediction system (HarmonEPS) with data assimilation. Bengtsson et al. (2017) and Frogner et al. (2019) provide descriptions of the cycle 40 HARMONIE-AROME CMC and the ensemble realisation of the ALADIN-HIRLAM NWP System in cycle 40 . The surface physics in HARMONIE-AROME cycle 43 is simulated by the SURFEX V8.1 surface model (Le Moigne, 2018). Cycle 43 of the ALADIN-HIRLAM NWP System is due for official release during 2020.

Extra source code required for MUSC, was developed by Météo-France (Malardel, 2004) and is already an integral part of the full ALADIN-HIRLAM NWP system. The source code is compiled in the same way for MUSC as the 3D system with namelists then controlling how the system is used. MUSC is in fact a pseudo-1D application of a 2D meridional vertical plane LAM configuration available in the system. It consists of four identical columns i.e. 4 points in the meridional direction with identical forcings and physics. A further description of namelist settings to activate MUSC and to apply large-scale forcings is provided in Malardel (2004).

\section{MUSC in HARMONIE-AROME}

We describe the various tools used within HARMONIEAROME in order to run a MUSC experiment. Information on how to create the MUSC input files and namelists is given in Sect. 3.1. How to handle the MUSC outputs is discussed in Sect. 3.2. The script system developed around the MUSC software and namelists is detailed in Sect. 3.3 and information on the MUSC virtual model is provided in Sect. 3.4.

\subsection{Preparing input for MUSC experiments}

In cycle 43 of the ALADIN-HIRLAM NWP System three input files are required to run a MUSC experiment within the HARMONIE-AROME modelling environment - an atmospheric, a surface and a physiography file. The latter two files may be empty if surface forcings are specified (and the surface model is switched off) but nevertheless, for technical reasons, three input files are expected. The files are required to be in Fichier Arpege (FA) binary format, a file format that originates from the ALADIN LAM and contains both spectral and grid point meteorological fields.

A very useful method for creating the required input files has been developed by Ulf Andrae, SMHI. This method uses atmospheric, surface and climate output files from a 3D HARMONIE-AROME experiment to generate 1D MUSC input data for any location within the domain of the 3D files. The tool, called gl (HIRLAM, 2019), can be used to extract atmospheric column, surface and physiographic data from the 3D files. gl is a multi-purpose tool, which uses ECMWF's ecCodes library (ECMWF-ecCodes, 2019) and FA I/O software included in the HARMONIE-AROME code. Other applications of gl include grid re-projection, data format conversion (GRIB, FA, NetCDF), the creation of post-processed meteorological parameters and the extraction of point data for verification purposes. Regarding the extraction of 1D data from 3D FA files the following meteorological parameters are included by default: surface geopotential, surface pressure and temperature, wind components, specific humidity, pressure departure, vertical divergence, cloud water, cloud ice, snow, rain, graupel and turbulent kinetic energy on model hybrid levels. Profiles of temperature, specific humidity and wind, equivalent to the profiles of these parameters at the location specified for MUSC are also extracted for forcing in the form of field nudging.

As well as extracting data from 3D HARMONIE-AROME files, gl can also be used to convert the extracted data from FA to ASCII format to facilitate changes to the model atmospheric, surface or physiography data and/or forcing information. Similarly, it can then be used to convert the edited or unedited ASCII files back to FA format for use in a MUSC experiment. This functionality is extremely useful for the design of sensitivity tests. A script called musc_convert.sh - see Sect. 3.3 for further details -is available within HARMONIE-AROME which includes the gl options for extracting data and converting back and forth between FA and ASCII formats. Alternatively, atmospheric input files can be created using the Météo-France ACADFA1D tool and an appropriate namelist, in which profiles of atmospheric fields and other parameters are defined.

As well as the three input files, appropriate atmospheric and surface namelists are needed to run a MUSC experiment. These namelists can be created manually but it is possible to make use of the existing namelist generation code embedded in the 3D HARMONIE-AROME scripting system. This ensures that relevant settings in the namelists remain consistent and up-to-date with the cycle of the code in use. The namelists are used to define various upper-air and surface physics options to use in the MUSC experiment as well as any required forcings (forcings are discussed in more detail later in this section).

MUSC experiments can be run in diagnostic or prognostic mode. Most of the aerosol and radiation sensitivity tests done to date using MUSC have been diagnostic-style experiments. By diagnostic we mean that we only run a single time-step experiment in which the state of the atmosphere and surface do not evolve from their initial values. In such experiments atmospheric forcings are not required. Experiments run in prognostic mode need forcings. Such forcings are included in the input atmospheric and surface files. Forcings can be extracted using the gl-method as discussed in Sect. 3.1. Using the ACADFA1D method any forcings need to be prescribed in the input namelist in order to generate the input FA file. 
Table 1. MUSC inputs, outputs and namelists.

\begin{tabular}{ll}
\hline Inputs & Method \\
\hline $\begin{array}{l}\text { Atmospheric input FA files } \\
\text { Surface and physiography input FA files }\end{array}$ & $\begin{array}{l}\text { gl-method or ACADFA1D-method } \\
\text { gl-method }\end{array}$ \\
\hline Namelists: & Method \\
\hline namelist_atm and namelist_sfx & manually create or use namelist generator \\
\hline Outputs: & Method \\
\hline FA format & gl to convert to ASCII or epygram by Météo-France \\
LFA format & Météo-France DDH tools that convert to ASCII format \\
& $\begin{array}{l}\text { Python script that calls the DDH tools and processes } \\
\text { ASCII output into NetCDF }\end{array}$ \\
\hline
\end{tabular}

This input namelist is not the same as the atmospheric and surface namelists used in a MUSC run.

The use and definition of the forcings or nudgings in the input FA files is specified in the atmospheric and surface experiment run namelists. Examples of forcings include geostrophic wind forcing; large scale advection of temperature, specific humidity, wind and vertical velocity; nudging of wind, temperature and specific humidity towards a defined profile; surface temperature, friction velocity and sensible and latent heat flux forcings. The namelists can specify if and when to apply the forcings or nudgings.

A summary of the MUSC inputs, namelists and outputs and how they are generated or handled is given in Table 1 . Further details on MUSC outputs are provided in Sect. 3.2.

\subsection{Handling MUSC output}

The MUSC atmospheric namelist controls the format of and frequency at which MUSC output files are generated. Outputs can be generated in FA, separate atmospheric and surface files, and LFA (Logiciel de Fichiers Autodocumentés) format. FA and LFA are IEEE self-documenting binary formats designed for the reading and writing of integer and real data. gl can be used to extract fields in ASCII format from the FA-format output files. Alternatively, gl can convert the FA files to grib (or ASCII) format for use in a wide range of software packages. On the other hand the LFA file format has many advantages, with the main one being that it is easy to include any additional variables in these output files by using MUSC subroutines by Météo-France. These subroutines are available by default in the ALADIN-HIRLAM NWP system. This possibility gives MUSC extreme advantages over the 3D system, where writing additional variables to output files is cumbersome and computationally heavy. The output LFA files can be readily converted to ASCII using the MétéoFrance DDH tools.

A tool has also been written in Python to combine and convert all LFA output files from a single MUSC run to a single NetCDF file. This script, convert_lfa_nc.py, calls the DDH tools to convert the output FA files to ASCII, then combines them to create the resulting NetCDF file. Since the variable names used in the model differ from standard abbreviations, the script calls a plain text file called variable_list.csv. This contains entries for the commonly encountered output variables, each of which includes the abbreviation used in the model, the common short name, long name, and units of the variables. If the script finds a variable in the output FA files listed in the variable_list.csv, it changes the name of the variable to the commonly used short name, and includes a long name and units in the resulting NetCDF file. If the variable is not listed in variable_list.csv, the script simply includes the output variable with its original name, and no long name or units. In this way, the script converts every variable in the output files and improves the readability of the resulting NetCDF variables where it can.

\subsection{HARMONIE-AROME MUSC utilities}

In this section we describe the scripts developed to run MUSC within the HARMONIE-AROME framework of the shared ALADIN-HIRLAM NWP System. This set-up has been tested at ECMWF and at the Irish Meteorological Service (Met Éireann), FMI, Met Norway, SMHI and KNMI. Table 2 gives a brief description of the scripts we use in the MUSC experiment process. To aid future users of the system we have included examples of command line usage of these scripts in Table A1.

\subsection{MUSC virtual machine}

Given MUSC's complexity and numerous dependencies, it has proven difficult for many users to install. To alleviate this problem, a Virtual Machine (VM) was created by Stephen Outten, NERSC, containing a fully installed and working version of the model. The VM consists of a full install of Ubuntu 16.04 OS with an installation of MUSC within the HARMONIE-AROME cycle 43 configuration as setup by Emily Gleeson and Eoin Whelan (Met Éireann, Ireland). This 
Table 2. MUSC scripts.

\begin{tabular}{ll}
\hline Script & Brief description \\
\hline musc_covert.sh & $\begin{array}{l}\text { This script has 3 usage options: (1) Extract 1D profiles from 3D HARMONIE-AROME files (extr3d) in FA format } \\
\text { (2) convert the 1D FA files to ASCII format for editing (fa2ascii) } \\
\text { (3) convert the ASCII back to FA for use in MUSC (ascii2fa). }\end{array}$ \\
\hline musc_setup.sh & $\begin{array}{l}\text { Sets up environment variables and paths in a similar manner to in the 3D HARMONIE-AROME environment. } \\
\text { Copies scripts to your MUSC experiment working directory. }\end{array}$ \\
\hline musc_compile.sh & Compiles MUSC using the HIRLAM consortium's makeup system. \\
\hline musc_run.sh & $\begin{array}{l}\text { Runs a MUSC experiment for a specified period in hours. The code also calls musc_namelists.sh to generate } \\
\text { up-to-date namelists required for the experiment. } \\
\text { See Sect. 3.1 for information on MUSC input files and namelists. }\end{array}$ \\
\hline
\end{tabular}

installation includes all required dependencies, along with numerous tools and a Python script to convert the output from a MUSC experiment into a single NetCDF file (Sect. 3.2). The MUSC VM can be downloaded from the HIRLAM System Documentation - MUSC web page (https://hirlam.org/ trac/wiki/HarmonieSystemDocumentation/MUSC, last access: 14 November 2020). MUSC installed in the VM includes a HARMONIE-AROME reference test case, and stepby-step instructions on the desktop on how to compile and run this experiment, how to setup new experiments, and how to create or modify the input driving files. While instructions are not explicitly provided for modifying the model code, individual experiments can be setup with modified code and compiled as usual within the MUSC VM. The VM is currently used at NERSC and the University of Bergen but it is anticipated that the user-base will continue to grow.

\section{HARMONIE-AROME single-column experiments}

In this section we have included some study cases that clearly illustrate the usefulness of the MUSC single-column modelling environment. The first of these involves the use of MUSC for sensitivity tests involving aerosols and radiation (Sect. 4.1). Because they are sensitivity tests, they are not compared to observations. Two examples of microphysicsrelated super-cooled liquid studies based on Engdahl et al. (2020b) are included in Sect. 4.2. The full suite of these microphysics-related tests and comparisons to observations are documented in the published papers (Engdahl et al., 2020b,a).

\subsection{Aerosol-radiation studies using MUSC}

For the studies discussed in this section MUSC input files were extracted from 3D HARMONIE-AROME output files using the gl-method discussed in Sect. 3.1. MUSC has been used for aerosol studies by Gleeson et al. (2016) [HARMONIE-AROME, cycle 40h1] and Rontu et al. (2020) [HARMONIE-AROME, cycle 43h1] in diagnostic mode i.e. where only output from the first time-step of the model integration was used. Gleeson et al. (2016) used observed aerosol optical depths (AODs) at different solar radiation wavelengths to constrain the radiative transfer parametrizations in a Russian wildfire case in summer 2010. Three radiation parametrizations available in experimental versions of HARMONIE-AROME were compared: an old ECMWF scheme (cy25, ECMWF, 2015), and two broadband schemes, ACRANEB (Geleyn et al., 2017; Mašek et al., 2016) and the HIRLAM radiation scheme (Rontu et al., 2017). Atmospheric and surface states were extracted from hourly output snapshots over a $24 \mathrm{~h}$ period from a 3D HARMONIE-AROME experiment. The aerosol load represented by aerosol optical depths (AODs) was found to be the most important factor influencing shortwave (SW) radiation fluxes at the Earth's surface. Each radiation scheme produced realistic results but only when observation-based wavelength-dependent aerosol optical properties were taken into account.

A more recent study by Rontu et al. (2020) focused on aerosol optical properties and their impact on radiative fluxes and temperature tendencies due to radiation. This required an upgrade to the aerosol input in HARMONIEAROME and MUSC experiments. Instead of AODs, aerosol concentrations were used in the form of mass mixing ratios (MMRs) of different aerosol species. These were extracted from 3D HARMONIE-AROME experiments, which in turn acquired the aerosol information either through the lateral boundaries (near-real-time (n.r.t.) data from Copernicus Atmosphere Monitoring Service, CAMS, Copernicus, 2020 ) or via monthly climatologies based on CAMS reanalysis data; Inness et al., 2019). MUSC experiments enabled the diagnosis of effects and interactions that could not easily be deduced from the results of 3D HARMONIE-AROME experiments. An example of this is the potentially significant role of even small concentrations of black carbon in the atmosphere. MUSC easily facilitates the inclusion of a much greater number of output variables. Such a wide range of 
variables and diagnostics compared to 3D experiment output makes a more detailed analysis possible.

The MUSC experiments by Gleeson et al. (2016) and Rontu et al. (2020) were run in diagnostic mode under clear-sky conditions in order to avoid complications relating to cloud-radiation interactions. The HIRLAM radiation scheme, one of the schemes used in the sensitivity studies, treats clouds and aerosols independently without accounting for secondary aerosol effects related to changes in cloud condensate and cloud particle size. Using this scheme, simplified cloud experiments over Badajoz were designed and run using MUSC in forecast mode with nudging profiles of temperature, specific humidity and wind speed towards their initial state. The same n.r.t. aerosol data and atmospheric state as described in Rontu et al. (2020) were used as input. A thin cloud layer was generated by doubling the specific humidity in the initial profile at six model levels between 960 and $920 \mathrm{hPa}$. The model's cloud microphysics parametrization then took care of the cloud formation, evolution and clearance.

The results (Fig. 1) illustrate the relative magnitude of the cloud and aerosol impacts on the surface and top-ofatmosphere (TOA) shortwave (SW) and longwave (LW) radiative fluxes. The difference in downward SW flux at the surface (SWDS) between clear-sky experiments that include aerosols and those without aerosols was about $170 \mathrm{~W} \mathrm{~m}^{-2}$ at the beginning of the experiment (Fig. 1a). Later the difference is smaller, but the incoming solar flux is also smaller. The relative impact of aerosols increases with decreasing solar elevation. When clouds were added, an additional reduction in SWDS was seen. During the first 20-30 min cloud formation from the available moisture occurs. After that a stable phase is observed, lasting more than one hour, and ends with the clearance of the cloud layer when the initial total cloud water content of $70 \mathrm{~g} \mathrm{~m}^{-2}$ has reduced to $0.1 \mathrm{~g} \mathrm{~m}^{-2}$. During this period the reduction in SWDS was up to $150 \mathrm{~W} \mathrm{~m}^{-2}$, which is about the same magnitude as the reduction due to the inclusion of aerosols. Under average atmospheric conditions aerosols typically reduce the surface clear-sky irradiance by less than $10 \%$ compared to the hypothetical case with no aerosols, while clouds can easily scatter and absorb half of the incoming solar radiation. At the TOA a corresponding increase in the outgoing SW radiation is seen (Fig. 1b). At that level, the impact of cloud dominates the impact of aerosols due to the higher reflectivity of clouds compared to the backward scattering of aerosols.

Regarding downward LW radiation at the surface (LWDS), the difference between clear-sky and cloudy experiments that include aerosols is four times larger than the difference between aerosol-including and aerosol-excluding clear-sky experiments (Fig. 1c). At the TOA, the impact of aerosols on outgoing LW radiation is of similar magnitude to the impact of clouds at the beginning of the simulation (Fig. 1d). After the clearance of the cloud around $1 \mathrm{~h} 40 \mathrm{~min}$ into the simulation, all radiation fluxes in the experiment that included both clouds and aerosols become equal to those in the aerosol-including clear-sky experiment. Note that any surface interactions were excluded by the setup of this experiment which assumed a slowly changing water surface as the lower boundary.

This example demonstrates the potential and limitations of MUSC when used in prognostic mode for testing model developments. In the aerosol studies, both HARMONIEAROME code modifications and new aerosol data were introduced. The impacts were tested under realistic atmospheric conditions, acquired from the output of a 3D experiment. All cloud and radiation parametrizations were activated but the surface interactions were limited by assuming a slowly changing water surface at the bottom of the atmospheric column. The evolution of the artificial cloud was controlled by the cloud microphysics parametrization. The temperature and humidity profiles were nudged towards the initial profiles, using the gl-based method of nudging in the input atmospheric file, in order to prevent drift during the time integration. When nudging was not applied, the cloud water content remained high and the cloud grew thicker throughout the simulation. This had a strong influence on the radiation fluxes and screen-level temperatures (not shown). Our results suggest that the magnitude of the impacts of cloud and aerosols on simulated radiation fluxes may be comparable when clouds and aerosols influence the radiative transfer independently. Large uncertainties are related to aerosol-cloud interactions because the mechanisms of such interactions are still poorly understood and quantified. Further MUSC experiments are planned in order to study the effects on radiation of changing cloud particle size and cloud water content for different aerosol species.

\subsection{Studies related to supercooled liquid water}

Both examples shown in this section were designed to investigate the generation and depletion of supercooled liquid water (SLW) in HARMONIE-AROME. An inadequate representation of SLW in NWP models can have implications for cloud cover, precipitation and downstream applications such as atmospheric icing forecasts which are crucial to the aviation industry.

Input files including relevant forcings were generated using the ACADFA1D approach only because surface parametrizations were not needed (the surface and physiography files were therefore empty). The examples shown in this section involve the isolation of microphysics with radiation, turbulence and boundary layer parametrizations switched off.

An example involving orographic lift is described in Sect. 4.2.1 and a freezing drizzle case is included in Sect. 4.2.2. Both examples are published and presented in full detail in Engdahl et al. (2020b) as well as the changes required to the ICE3 microphysics parametrization (Cohard and Pinty, 2000a,b) in HARMONIE-AROME that are 


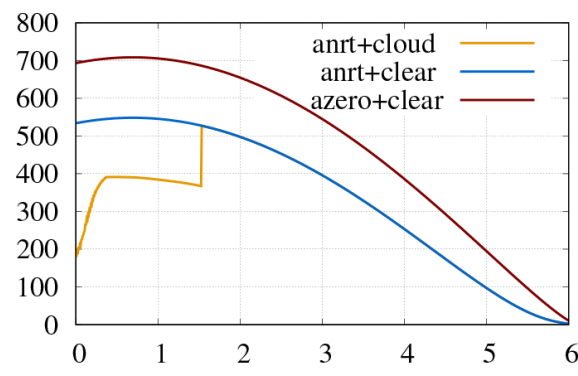

(a)

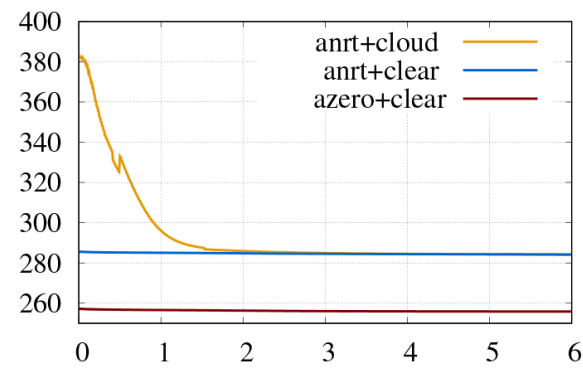

(c)

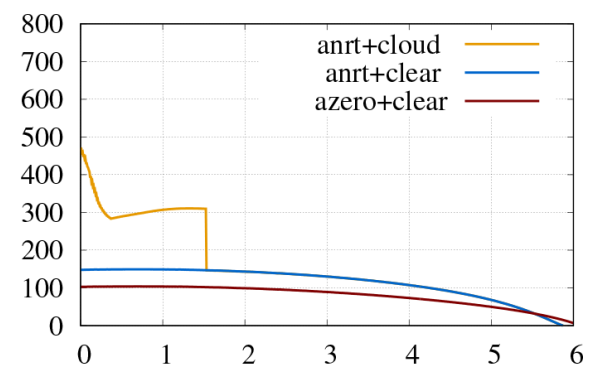

(b)

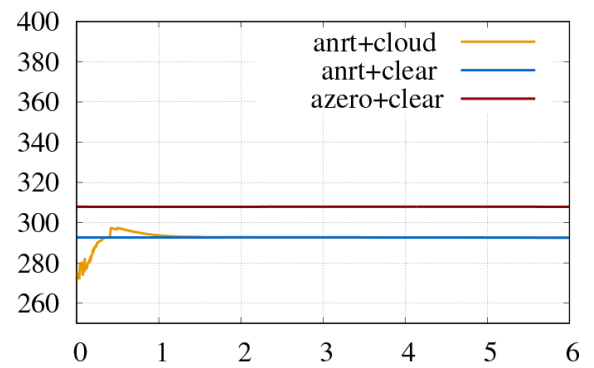

(d)

Figure 1. Evolution of radiative fluxes $\left(y\right.$-axis, $\left.\mathrm{W} \mathrm{m}^{-2}\right)$ as a function of time $(x$-axis, $\mathrm{h})$ in a MUSC experiment over Badajoz in Spain done using the HLRADIA radiation scheme. No aerosols or clouds (red), aerosols (blue), aerosols and clouds (yellow). (a) Downward SW radiation at the surface (SWDS), (b) upward SW radiation at the TOA (SWUT), (c) downward LW radiation at the surface (LWDS), (d) upward LW radiation at the TOA (LWUT). The downward SW radiation at the TOA at Badajoz $\left(38.9^{\circ} \mathrm{N}, 7^{\circ} \mathrm{W}\right)$ was $895 \mathrm{~W} \mathrm{~m}{ }^{-2}$ at 12:00 UTC on 22 February 2017, when the experiments were started under the given atmospheric conditions and aerosol distribution.

needed to improve the representation of SLW. The results of the single-column experiments shown here were obtained using reference cycle 43 HARMONIE-AROME source code i.e. the code does not yet include any of the the upgrades suggested in Engdahl et al. (2020b).

The freezing drizzle and orographic lift studies discussed in the following sections focus on the ICE3 microphysics scheme in HARMONIE-AROME, which is based on Cohard and Pinty (2000a,b) with physics that can be traced back to Lin et al. (1983). The main role of the cloud microphysics scheme is to create and dissipate clouds and precipitation through various sources and sinks of water vapour, liquid and ice particles. The heating and cooling as a result of microphysical processes is also taken into account. The representation of cloud water in NWP models is an on-going challenge at sub-zero temperatures because most models, including HARMONIE-AROME, favour ice over SLW.

As discussed in Liu et al. (2011) microphysics schemes based on the physics of Lin et al. (1983) represent SLW poorly. Such schemes initiate ice from water vapour too quickly when supersaturation with respect to ice is reached. They also cause water droplets to freeze prematurely. The representation of SLW is considerably better in the Morrison et al. (2009) and Thompson et al. (2008) schemes. The results presented in Sect. 4.2.1 and 4.2.2 therefore focus on microphysics-related output.

\subsubsection{Orographic lift study}

This idealised case represents a simple example of orographic lift and is based on studies by Thompson et al. (2008), Thompson et al. (2004) and Thompson and Eidhammer (2014) done using the WRF (Weather Research and Forecasting) model. It was designed to mimic a parcel of air being lifted by the orography of a bell-shaped hill. This orographic lift is accounted for in MUSC using a sinusoidal variation in the vertical velocity forcing with respect to time and altitude as shown in Fig. 2a. The atmospheric sounding for this case stems from the Improvement of Microphysical Parametrization through Observational Verification Experiment (IMPROVE-2) shown in Stoelinga et al. (2003). With this set-up a significant amount of SLW is expected.

The ICE3 scheme in HARMONIE-AROME can be considered as an "ice-friendly" scheme (Frogner et al., 2019). In this experiment when the relative humidity with respect to ice exceeded $100 \%$ cloud ice started to form due to primary nucleation of ice by vapour deposition (blue contour shades in Fig. 3a). During the first hour of the experiment ice growth was small but water saturation was achieved and cloud droplets grew (red contour shades in Fig. 3a). As the experiment progressed the amount of cloud ice increased as vapour was continually supplied by the prescribed uplift velocity. At the same time cloud liquid water decreased (red contour shades in Fig. 3a) through riming of snow, graupel 

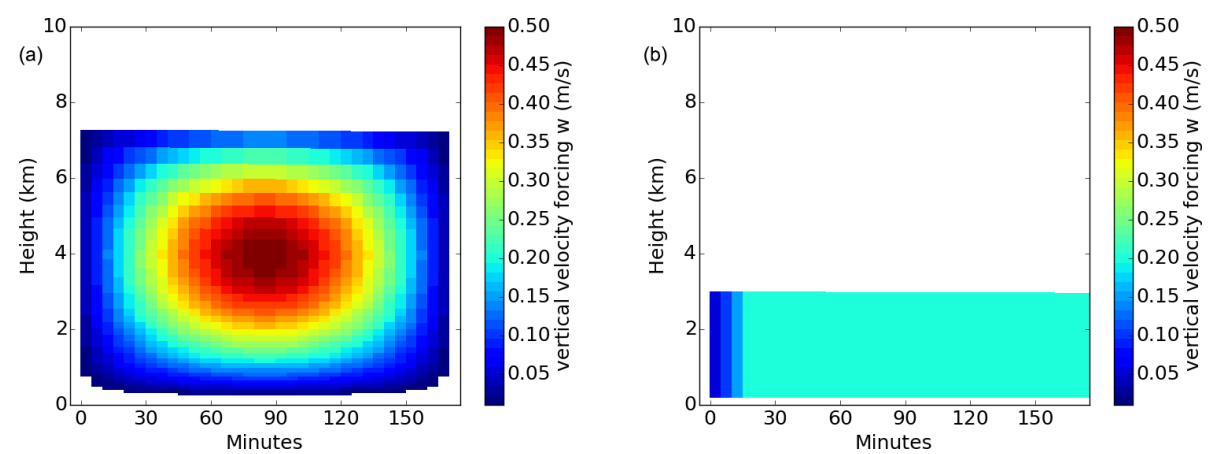

Figure 2. Time-height cross-section of the vertical velocity forcing used for the single-column (a) orographic lift case and (b) freezing drizzle case.
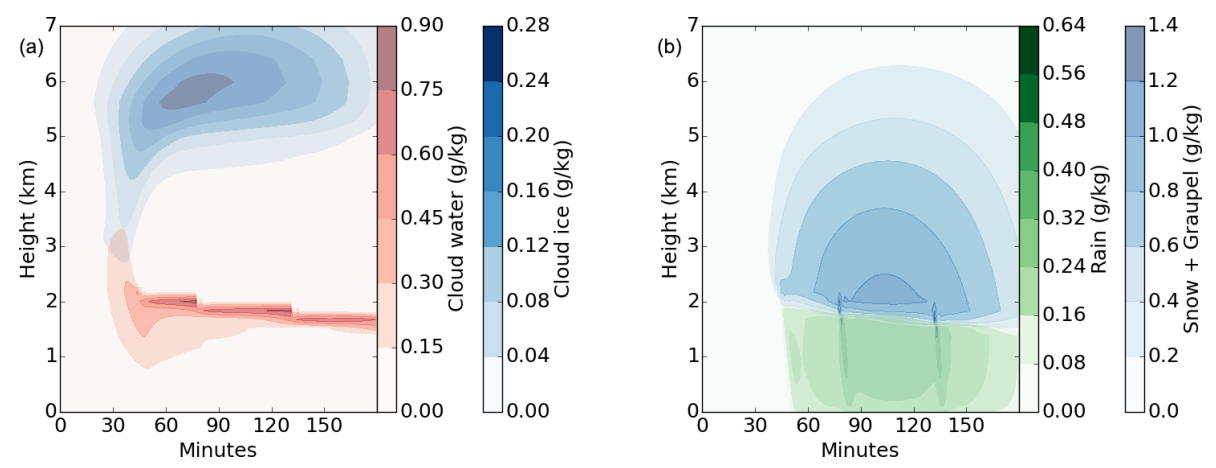

Figure 3. Time-height cross-section of (a) cloud water and cloud ice and (b) rain, snow+graupel in the single-column orographic lift experiment.

formation and subsequent riming of graupel (blue contour shades in Fig. 3b). The ice particles then fell to the melting level where they were converted to rain (green contour shades in Fig. 3b).

In reality cloud initiation should have occurred much later with supercooled rain forming instead. This experiment highlights a deficiency in HARMONIE-AROME than can be rectified using the microphysics upgrades discussed in detail in Engdahl et al. (2020b). Comparisons to observations in corresponding 3D experiments are included in (Engdahl et al., 2020a).

\subsubsection{Freezing drizzle example}

This case is based on an idealised version of a high-impact freezing drizzle event that occurred near Oslo in Norway on 15 January 2018. The event caused severe disruption to flights at Oslo International Airport. HARMONIE-AROME predicted snowfall rather than freezing drizzle and freezing rain. A radiosonde sounding confirmed that conditions in the area were perfect for the formation of freezing rain/drizzle. As in the orography case input FA files were prepared using the ACADFA1D-method with the vertical velocity forcing prescribed as shown in Fig. $2 b$.
In this example we see cloud water quickly forming over the first $30 \mathrm{~min}$ or so of the experiment (Fig. 4a, red shaded contours) before decreasing again at the same time as snow and graupel starts to form (Fig. 4b). Similar to the orographic lift case, cloud ice forms quickly and converts to snow. The snow starts to collect cloud water which introduces graupel. The snow and graupel collect most of the remaining water, which inhibits the formation of freezing drizzle and favours precipitation in the form of snow. This is contrary to observations and again highlights a deficiency in the default microphysics scheme in HARMONIE-AROME.

\section{Conclusions}

Single-column models are widely used to develop and test physical parametrizations in NWP and climate models. In this paper we have focused on using the ALADIN-HIRLAM single-column model, MUSC, within the HARMONIEAROME canonical model configuration of the ALADINHIRLAM NWP system.

In particular, we have mainly focused on some of the tools and scripts prepared within this framework including the gl tool used to extract atmospheric profiles and surface and physiographic information from 3D HARMONIE-AROME files for use in MUSC experiments. This tool is particularly 

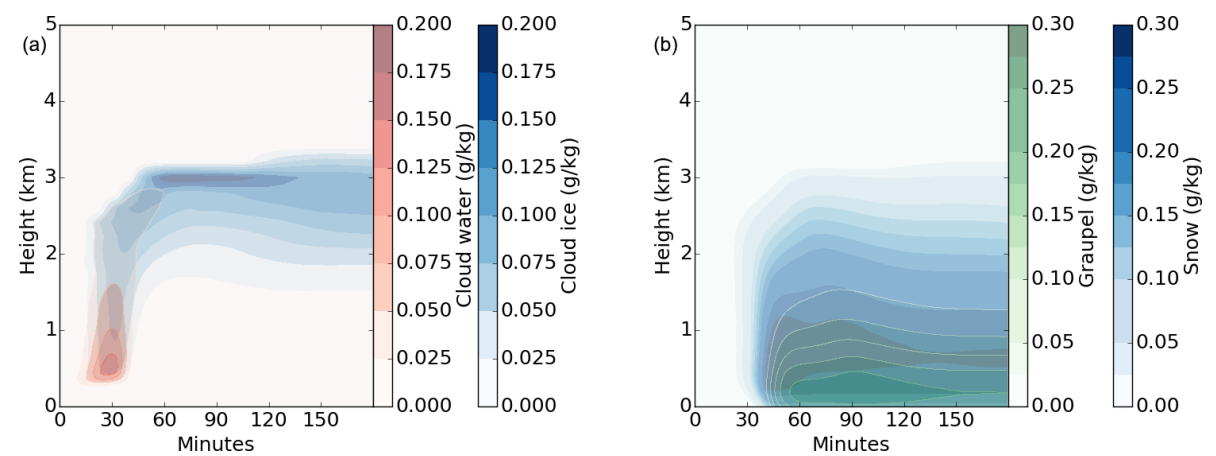

Figure 4. Time-height cross-section of (a) cloud water and cloud ice and (b) rain, snow + graupel in the single-column freezing drizzle experiment.

useful as it allows MUSC input files to be converted from the more cumbersome FA format to ASCII for ease of editing. We have included information and descriptions on the userfriendly scripts we have developed, that surround existing tools available within HARMONIE-AROME, to help newusers of MUSC. Finally, we presented details on a MUSC virtual machine. As well as the tools, we have included examples of the application of MUSC to advertise how it can be used more widely for the development of physical parametrizations in the ALADIN-HIRLAM NWP system. Comparisons with observations were not suitable for the radiation/aerosol example included while those for the supercooled liquid cases are included in the detailed full paper on these MUSC orographic and freezing drizzle cases.

Currently, there is limited documentation available on MUSC besides a technical document by Malardel (2004) and presentations delivered at an AROME training course in 2008 (AROME, 2008), a MUSC training course at FMI in 2011 (MUSC, 2011a,b) and a Helsinki numerical meteorology course a few years later. Interest in using MUSC in both HIRLAM and ALADIN countries is growing and therefore the need for more extensive documentation and a userguide on MUSC is evident.
Large meteorological services such as Météo-France and the UK Met Office maintain a suite of idealised intercomparison cases to cover a wide variety of weather conditions. Such cases are used to evaluate the physical parametrizations with each upgrade of their models. A similar testbed approach, involving several idealised cases covering a wide range of weather scenarios, would provide great benefits if used when evaluating HARMONIE-AROME model upgrades. Such a set-up requires considerable resources in term of time and expertise. Nevertheless, this is something we should strive towards because the lack of such a suite of test cases hampers the use of MUSC more widely within the model developer community.

Currently, we have gathered a small collection of study cases - as well as the ones shown in this paper, we have a few fog-related and aerosol-related cases. We maintain these as part of the system and they should be viewed as the first step in developing a more complete testbed of cases that can be easily used by scientists developing model physics. 
Appendix A: MUSC script usage

Table A1. MUSC script usage.

\begin{tabular}{|c|c|}
\hline Script & Usage \\
\hline musc_convert.sh & $\begin{array}{l}. / \text { musc_convert.sh }-\mathrm{d}<\text { folder containing the files to be converted }>-\mathrm{c}<\text { type of conversion }> \\
-\mathrm{n}<\text { expt ID on the MUSC input files }{ }^{1}>\left[-l<\text { latitude,longitude }>^{2}\right]\left[-\mathrm{t}<\text { time_hour }>^{3}\right]\end{array}$ \\
\hline musc_setup.sh & $<$ path to develop $>/$ develop/util/musc/scr/musc_setup.sh $-\mathrm{r}<$ path to develop $>/$ develop $-\mathrm{c}<$ your configuration $>$ \\
\hline musc_compile.sh &.$/$ musc_compile.sh $-\mathrm{n}<$ number of processors $>$ \\
\hline musc_run.sh & $\begin{array}{l}. / \text { musc_run.sh }-\mathrm{d}<\text { directory of subfolders of experiment input data }>-\mathrm{t}<\text { musc study case }> \\
-\mathrm{n}<\text { expt ID on the MUSC input files }{ }^{1}>-1<\text { experiment length in hours }\left[-N^{4}\right]\left[-\mathrm{e}<\text { path to ecoclimap land cover data }>^{5}\right]\end{array}$ \\
\hline
\end{tabular}


Code availability. The HARMONIE-AROME source code is available by licence for research purposes.

Author contributions. All authors contributed to the writing of this paper. UA developed and maintains the HIRLAM gl tool. EW, EG and UA developed and maintain the script system used to run MUSC in the HARMONIE-AROME CMC. LR and EG have been involved in designing and testing radiation and aerosol-related MUSC experiments. BJKE designed and ran the SLW microphysics experiments. SO set-up and tested GABLS1 (not included) in the MUSC HARMONIE-AROME cycle 43 environment and created the MUSC virtual machine.

Disclaimer. This paper is not a reference paper for MUSC but instead describes tools and scripts developed to make the use of MUSC, within the HARMONIE-AROME environment, more userfriendly. The paper is also about the application of MUSC more widely for the development of physical parametrizations within HARMONIE-AROME. Malardel (2004) should be referred to if a reference for details on the core of MUSC is required.

Special issue statement. This article is part of the special issue "19th EMS Annual Meeting: European Conference for Applied Meteorology and Climatology 2019”. It is a result of the EMS Annual Meeting: European Conference for Applied Meteorology and Climatology 2019, Lyngby, Denmark, 9-13 September 2019.

Acknowledgements. The authors would like to acknowledge the support of the international HIRLAM-C programme.

Financial support. Stephen Outten was supported by the Norwegian Research Council project no. 280573 "Advanced models and weather prediction in the Arctic: enhanced capacity from observations and polar process representations (ALERTNESS)". Bjørg Jenny Kokkvoll Engdahl was funded by WISLINE, NFR grant number: 244106.

Review statement. This paper was edited by Kristian Pagh Nielsen and reviewed by Bert Holtslag and Wim De Rooy.

\section{References}

AROME: 2008 - 2nd AROME Training Course, available at: http: //www.umr-cnrm.fr/gmapdoc/spip.php?rubrique64 (last access: 14 November 2020), 2008.

Bengtsson, L., Andrae, U., Aspelien, T., Batrak, Y., Calvo, J., de Rooy, W., Gleeson, E., Hansen-Sass, B., Homleid, M., Hortal, M., Ivarsson, K.-I., Lenderink, G., Niemelä, S., Nielsen, K. P., Onvlee, J., Rontu, L., Samuelsson, P., Muñoz, D. S., Subias, A., Tijm, S., Toll, V., Yang, X., and Køltzow, M. Ø.: The HARMONIE-AROME Model Configuration in the ALADINHIRLAM NWP System, Mon. Weather Rev., 145, 1919-1935, https://doi.org/10.1175/MWR-D-16-0417.1, 2017.

Bosveld, F., Baas, P., Steeneveld, G., Holtslag, A., Angevine, W., Bazile, E., de Bruijn, E., Deacu, D., Edwards, J., Ek, M., Larson, V., Pleim, J., Raschendorfer, M., and Svensson, G.: The Third GABLS Intercomparison Case for Evaluation Studies of Boundary-Layer Models. Part B: Results and Process Understanding, Bound.-Lay. Meteorol., 152, 157-187, https://doi.org/10.1007/s10546-014-9919-1, 2014.

Cohard, J.-M. and Pinty, J.-P.: A comprehensive twomoment warm microphysical bulk scheme. I: Description and tests, Q. J. Roy. Meteorol. Soc., 126, 1815-1842, https://doi.org/10.1002/qj.49712656613, 2000a.

Cohard, J.-M. and Pinty, J.-P.: A comprehensive two-moment warm microphysical bulk scheme. II: 2D experiments with a nonhydrostatic model, Q. J. Roy. Meteorol. Soc., 126, 1843-1859, https://doi.org/10.1002/qj.49712656614, 2000b.

Copernicus: Copernicus Atmosphere Monitoring Service (CAMS) Data, available at: https://atmosphere.copernicus.eu/data, last access: 14 November 2020.

Cuxart, J., Holtslag, A. A. M., Beare, R. J., Bazile, E. B. A., Cheng, A., L. C., Ek, M., Freedman, F., Hamdi, R. K. A., Kitagawa, H., Lenderink, G., Lewellen, D., Mailhot, J., Mauritsen, T., Perov, V., Schayes, G., Steeneveld, G.-J., Svensson, G., Taylor, P., Weng, W., Wunsch, S., and Xu, K.-M.: SingleColumn Model Intercomparison for a Stably Stratified Atmospheric Boundary Layer, Bound.-Lay. Meteorol., 118, 273-303, https://doi.org/10.1007/s10546-005-3780-1, 2006.

ECMWF: ECMWF IFS documentation Chapter 2, available at: http://www.ecmwf.int/sites/default/files/elibrary/2015/ 9211-part-iv-physical-processes.pdf (last access: 14 November 2020), 2015.

ECMWF-ecCodes: ecCodes Home, available at: https://confluence. ecmwf.int/display/ECC (last access: 14 November 2020), 2019.

Engdahl, B. J. K., Nygaard, B. E. K., Losnedal, V., Thompson, G., and Bengtsson, L.: Effects of the ICE-T microphysics scheme in HARMONIE-AROME on estimated ice loads on transmission lines, Cold Reg. Sci. Technol. 179, 103139, https://doi.org/10.1016/j.coldregions.2020.103139, 2020a.

Engdahl, B. J. K., Thompson, G., and Bengtsson, L.: Improving the representation of supercooled liquid water in the HARMONIE-AROME weather forecast model, Tellus A, 72, 118, https://doi.org/10.1080/16000870.2019.1697603, 2020 b.

Firl, G., Carso, L., Bernardet, L., and Heinzeller, D.: Global Model Test Bed Single Column Model (SCM) User and Technical Guide v3.0, Tech. rep., National Center for Atmospheric Research and Developmental Testbed Center, NOAA/ESRL Global Systems Division, Developmental Testbed Center and 
CIRES/CU, available at: https://dtcenter.org/sites/default/files/ community-code/ccpp/GMTB/scm-ccpp-guide-v4.0.pdf (last access: 14 November 2020), 2019.

Frogner, I.-L., Andrae, U., Bojarova, J., Callado, A., Escribà, P., Feddersen, H., Hally, A., Kauhanen, J., Randriamampianina, R., Singleton, A., Smet, G., van der Veen, S., and Vignes, O.: HarmonEPS - The HARMONIE Ensemble Prediction System, Weather Forecast., 34, 1909-1937, https://doi.org/10.1175/WAF-D-19-0030.1, 2019.

Geleyn, J.-F., Mašek, J., Brožková, R., Kuma, P., Degrauwe, D., Hello, G., and Pristov, N.: Single interval longwave radiation scheme based on the net exchanged rate decomposition with bracketing, Q. J. Roy. Meteorol. Soc., 143, 1313-1335, https://doi.org/10.1002/qj.3006, 2017.

Gleeson, E., Toll, V., Nielsen, K. P., Rontu, L., and Mašek, J.: Effects of aerosols on clear-sky solar radiation in the ALADINHIRLAM NWP system, Atmos. Chem. Phys., 16, 5933-5948, https://doi.org/10.5194/acp-16-5933-2016, 2016.

HIRLAM: Post processing with gl_grib_api, available at: https://hirlam.org/trac/wiki/HarmonieSystemDocumentation/ PostPP/gl_grib_api (last access: 14 November 2020), 2019.

Inness, A., Ades, M., Agustí-Panareda, A., Barré, J., Benedictow, A., Blechschmidt, A.-M., Dominguez, J. J., Engelen, R., Eskes, H., Flemming, J., Huijnen, V., Jones, L., Kipling, Z., Massart, S., Parrington, M., Peuch, V.-H., Razinger, M., Remy, S., Schulz, M., and Suttie, M.: The CAMS reanalysis of atmospheric composition, Atmo. Chem. Phys., 19, 3515-3556, https://doi.org/10.5194/acp-19-3515-2019, 2019.

Koski, H.: Weather models developed through cloud computing, available at: https://www.csc.fi/en/web/atcsc/-/ pilvilaskenta-avuksi-saamallien-kehitykseen (last access: 14 November 2020), 2017.

Le Moigne, P.: SURFEX Scientific Documentation, Tech. rep., available at: https://www.umr-cnrm.fr/surfex/IMG/pdf/surfex_ scidoc_v8.1.pdf (last access: 14 November 2020), 2018.

Lin, Y.-L., Farley, R. D., and Orville, H. D.: Bulk Parameterization of the Snow Field in a Cloud Model, J. Clim. Appl. Meteorol., 22, 1065-1092, https://doi.org/10.1175/15200450(1983)022<1065:BPOTSF>2.0.CO;2, 1983.

Liu, C., Ikeda, K., Thompson, G., Rasmussen, R., and Dudhia, J.: High-Resolution Simulations of Wintertime Precipitation in the Colorado Headwaters Region: Sensitivity to Physics Parameterizations, Mon. Weather Rev., 139, 3533-3553, https://doi.org/10.1175/MWR-D-11-00009.1, 2011.

Malardel, S.: MUSC:(Modèle Unifé, Simple Colonne) for Arpege-Aladin-Arome-Alaro-Hirlam-(IFS)(CY31T1 version), Tech. rep., Météo-France/CNRM, France, 2004.

Mašek, J., Geleyn, J.-F., Brožková, R., Giot, O., Achom, H. O., and Kuma, P.: Single interval shortwave radiation scheme with parameterized optical saturation and spectral overlaps, Q. J. Roy. Meteorol. Soc., 142, 304-326, https://doi.org/10.1002/qj.2653, 2016.

Morrison, H., Thompson, G., and Tatarskii, V.: Impact of Cloud Microphysics on the Development of Trailing Stratiform Precipitation in a Simulated Squall Line: Comparison of One- and Two-Moment Schemes, Mon. Weather Rev., 137, 991-1007, https://doi.org/10.1175/2008MWR2556.1, 2009.

Mottram, R., Nielsen, K. P., Gleeson, E., and Yang, X.: Modelling Glaciers in the HARMONIE-AROME NWP model, Adv.
Sci. Res., 14, 323-334, https://doi.org/10.5194/asr-14-323-2017, 2017.

MUSC: Hirlam-B working days on HARMONIE-MUSC, available at: http://netfam.fmi.fi/muscwd11/ (last access: 14 November 2020), 2011a.

MUSC: Hirlam-B working days on HARMONIE-MUSC - Presentations, available at: http://netfam.fmi.fi/muscwd11/Agenda.html (last access: 14 November 2020), 2011b.

Neggers, R. and Siebesma, A.: The KNMI Parametrization Testbed User's Guide Version 2, unpublished, 2010.

Neggers, R. A. J., Ackerman, A. S., Angevine, W. M., Bazile, E., Beau, I., Blossey, P. N., Boutle, I. A., de Bruijn, C., Cheng, A., van der Dussen, J., Fletcher, J., Dal Gesso, S., Jam, A., Kawai, H., Cheedela, S. K., Larson, V. E., Lefebvre, M.-P., Lock, A. P., Meyer, N. R., de Roode, S. R., de Rooy, W., Sandu, I., Xiao, H., and Xu, K.-M.: Single-Column Model Simulations of Subtropical Marine Boundary-Layer Cloud Transitions Under Weakening Inversions, J. Adv. Model. Earth Syst., 9, 2385-2412, https://doi.org/10.1002/2017MS001064, 2017.

Nielsen, K. P., Gleeson, E., and Rontu, L.: Radiation sensitivity tests of the HARMONIE 37h1 NWP model, Geosci. Model Dev., 7, 1433-1449, https://doi.org/10.5194/gmd-7-1433-2014, 2014.

Rontu, L., Gleeson, E., Räisänen, P., Pagh Nielsen, K., Savijärvi, H., and Hansen Sass, B.: The HIRLAM fast radiation scheme for mesoscale numerical weather prediction models, Adv. Sci. Res., 14, 195-215, https://doi.org/10.5194/asr-14-195-2017, 2017.

Rontu, L., Gleeson, E., Martin Perez, D., Pagh Nielsen, K., and Toll, V.: Sensitivity of Radiative Fluxes to Aerosols in the ALADINHIRLAM Numerical Weather Prediction System, Atmosphere, 11, 205, https://doi.org/10.3390/atmos11020205, 2020.

Stoelinga, M. T., Hobbs, P. V., Mass, C. F., Locatelli, J. D., Colle, B. A., Houze, R. A., Rangno, A. L., Bond, N. A., Smull, B. F., Rasmussen, R. M., Thompson, G., and Colman, B. R.: Improvement of Microphysical Parameterization through Observational Verification Experiment, B. Am. Meteorol. Soc., 84, 1807-1826, https://doi.org/10.1175/BAMS-84-12-1807, 2003.

Svensson, G., Holtslag, A. A. M., Kumar, V., Mauritsen, T., Steeneveld, G. J., Angevine, W. M., Bazile, E., Beljaars, A., de Bruijn, E. I. F., Cheng, A., Conangla, L., Cuxart, J., Ek, M., Falk, M. J., Freedman, F., Kitagawa, H., Larson, V. E., Lock, A., Mailhot, J., Masson, V., Park, S., Pleim, J., Söderberg, S., Weng, W., and Zampieri, M.: Evaluation of the Diurnal Cycle in the Atmospheric Boundary Layer Over Land as Represented by a Variety of Single-Column Models: The Second GABLS Experiment, Bound.-Lay. Meteorol., 140, 177-206, https://doi.org/10.1007/s10546-011-9611-7, 2011.

Termonia, P., Fischer, C., Bazile, E., Bouyssel, F., Brožková, R., Bénard, P., Bochenek, B., Degrauwe, D., Derková, M., El Khatib, R., Hamdi, R., Mašek, J., Pottier, P., Pristov, N., Seity, Y., Smolíková, P., Španiel, O., Tudor, M., Wang, Y., Wittmann, C., and Joly, A.: The ALADIN System and its canonical model configurations AROME CY41T1 and ALARO CY40T1, Geosci. Model Dev., 11, 257-281, https://doi.org/10.5194/gmd-11-2572018, 2018.

Thompson, G. and Eidhammer, T.: A Study of Aerosol Impacts on Clouds and Precipitation Development in a Large Winter Cyclone, J. Atmos. Sci., 71, 3636-3658, https://doi.org/10.1175/JAS-D-13-0305.1, 2014. 
Thompson, G., Rasmussen, R. M., and Manning, K.: Explicit Forecasts of Winter Precipitation Using an Improved Bulk Microphysics Scheme. Part I: Description and Sensitivity Analysis, Mon. Weather Rev., 132, 519-542, https://doi.org/10.1175/15200493(2004)132<0519:EFOWPU>2.0.CO;2, 2004.

Thompson, G., Field, P. R., Rasmussen, R. M., and Hall, W. D.: Explicit Forecasts of Winter Precipitation Using an Improved Bulk Microphysics Scheme. Part II: Implementation of a New Snow Parameterization, Mon. Weather Rev., 136, 5095-5115, https://doi.org/10.1175/2008MWR2387.1, 2008.

Vignon, E., Hourdin, F., Genthon, C., Gallée, H., Bazile, E., Lefebvre, M.-P., Madeleine, J.-B., and Van de Wiel, B. J. H.: Antarctic boundary layer parametrization in a general circulation model: 1-D simulations facing summer observations at Dome C, J. Geophys. Res.-Atmos., 122, 6818-6843, https://doi.org/10.1002/2017JD026802, 2017.
Walters, D. N., Best, M. J., Bushell, A. C., Copsey, D., Edwards, J. M., Falloon, P. D., Harris, C. M., Lock, A. P., Manners, J. C., Morcrette, C. J., Roberts, M. J., Stratton, R. A., Webster, S., Wilkinson, J. M., Willett, M. R., Boutle, I. A., Earnshaw, P. D., Hill, P. G., MacLachlan, C., Martin, G. M., Moufouma-Okia, W., Palmer, M. D., Petch, J. C., Rooney, G. G., Scaife, A. A., and Williams, K. D.: The Met Office Unified Model Global Atmosphere 3.0/3.1 and JULES Global Land 3.0/3.1 configurations, Geosci. Model Dev., 4, 919-941, https://doi.org/10.5194/gmd-4919-2011, 2011. 